\title{
Effect of Diet Counseling on Anthropometric Indices and Dietary Intake of the Head and Neck Cancer Patients Undergoing Chemo-Radiotherapy
}

\author{
Debjani Sarkar, Pallavi Shettigar, HY Prahlad
}

\begin{abstract}
Malnutrition is common in patients with head and neck cancer due to cancer cachexia, anti-cancer therapies, impairment in food intake due to the tumor etc. This study aims at studying the effect of diet counseling intervention on dietary intake and anthropometric indices. Experimental design with only one experimental group was conducted on 14 head and neck cancer patients who were admitted for chemo-radiotherapy. Detailed assessment of anthropometry and diet was done in the before, during and after the diet counseling intervention of 7 weeks. There was mean weight improvement of $2 \mathrm{~kg}$ ( $p<0.001)$ during the intervention period that can be attributed to a significant increase in the dietary intake of energy $(p=0.034)$, protein $(p=0.011)$, calcium $(p<0.001)$, zinc $(p=0.041)$, vitamin $C$ $(p=0.046)$ and vitamin $A(p=0.019)$. However there was no statistically significant improvement in the mid-upper arm circumference (MUAC). This increase may be a sign of improvement of nutritional status as normally cancer patients tend to show a decrease in MUAC. This indicates the success of the diet counseling intervention. An even greater improvement in these parameters can be achieved if intervention is provided before the initiation of chemoradiotherapy and has to be continued even after the therapy is complete.
\end{abstract}

Keywords-Head and neck cancer, malnutrition, diet counseling, changes in anthropometric indices, changes in dietary intake.

\section{INTRODUCTION}

Malnutrition is common among the patients with head and neck cancer undergoing chemoradiotherapy (CRT). This is attributed to tumor type, site of the tumor, anti-cancer treatment; various symptoms the patients develop during the treatment which ultimately leads to the reduced food intake and weight loss of the patients. In 2011, there were 6,767 new cases of oral cancer in the UK: 4,510 (67\%) in men and 2,257 (33\%) in women, giving a male: female ratio of around 20:10. The crude incidence rate shows that there are 15 new oral cancer cases for every 100,000 males in the UK, and 7 for every 100,000 females[ ]. Malnutrition is the most common comorbidity in cancer patient population. Studies have demonstrated that anywhere from $30 \%$ to $87 \%$ of cancer patients are diagnosed with malnutrition with 30$60 \%$ of cancer patients diagnosed with protein calorie malnutrition with higher rates of as much as $80 \%$ in

Revised Manuscript Received on 05 August, 2019

Debjani Sarkar, Dietetics and Applied Nutrition, Department of Allied Hospitality Studies, Welcom group Graduate School of Hotel Karnataka, India (e-mail: sarkardebjani614@gmail.com)

Pallavi Shettigar, Dietetics and Applied Nutrition, Department of Allied Hospitality Studies, Welcom group Graduate School of Hotel Administration, Manipal Academy of Higher Education, Manipal, Karnataka, India (e-mail: pallavi.wgsha@ manipal.edu)

HY Prahlad, Radiotherapy \& Oncology Department, ShirdiSaibaba Hospital, Kasturba Medical College, Manipal Academy of Higher Education, Manipal, Karnataka, India (e-mail: hyprahlad@gmail.com) Administration, Manipal Academy of Higher Education, Manipal,

esophageal cancer patients[ ]. Anticancer treatments like radiation therapy, chemotherapy or combination therapy i.e. chemoradiotherapy may have an adverse effect like weight loss, xerostomia, loss of taste, impaired swallowing function, mucositis, pharyngitis, nausea and vomiting that can adversely affect the food intake of a person. In a study it shows that the toxic effects can lead to grade 3 or higher mucositis in the majority of patients undergoing chemoradiotherapy (CRT), whilst only $20 \%$ to $30 \%$ of patients treated with conventional radiotherapy (RT) alone will develop mucositis[ ]. Another study shows that in addition to general symptoms caused by cachexia, such as loss of appetite, early satiety and changes in smell and taste, head and neck cancer patients often suffer from oral symptoms, caused by the tumor, or as a side effect of head and neck cancer treatment. The most common oral symptoms include taste disturbances [ ]. Weight reduction up to $5 \%$ or more is mostly conspicuous among the patients due to cachexia as well as due to anti-cancer treatment. A cross sectional study conducted on 112 patients with oral cancer showed that a mean decline of approximately $3 \mathrm{kgs}$ of body weight was observed among the patients pre-treatment and they claimed that the weight loss among the patients were mostly caused by the swallowing problem.[ ] Apart from that, reduction in mid-upper arm circumference (MUAC) which is a great indicator of muscle wasting is noted among these patients. More or less all the patients with head and neck lose weight and have a drop in nutritional status. Thus, nutritional screening is very important for these kinds of patients to detect malnutrition at an early stage. [ ]The Oncology Nutrition Dietetic Practice Group of the American Dietetic Association adopted the Scored PG-SGA as a standard nutrition assessment tool for cancer patients.[ ] A study shows that early nutrition intervention in patients with HNC (Head and Neck Cancer) receiving chemoradiotherapy resulted in an improved treatment tolerance and fewer admissions to hospital[ ]. Thus, nutritional counseling seems to be effective in the betterment of the overall health status of the patient. It helps to replenish the nutrient losses in the body and also helps to gain weight slowly but effectively as it improves the food intake of the patients. The patients' anthropometric as well as biochemical parameters may tend to improve after diet counseling as it improves their intake and ultimately the quality of life yet it takes an extended period of time to show the improvement. 


\section{METHODOLOGY}

Objective: The main objectives of the study are to determine the effect of nutritional intervention on the dietary intake and the anthropometric indices of the affected head and neck cancer patients undergoing chemoradiotherapy.

The methodology of the study is shown in a schematic diagram below:

Study design: Experimental Study

Study Location: Shirdi Saibaba Cancer Hospital and Research Centre, KMC, Manipal

Selection of Samples- Patients with head and neck cancer undergoing chemora diotherapy is included while patients undergoing surgery exclusively were excluded.

Collection Of pre-treatment and counselling-data: General Information like name, age, gender, religion, family history, medical history etc, anthropometric measurements, dietary habits and 3 days diet recall.

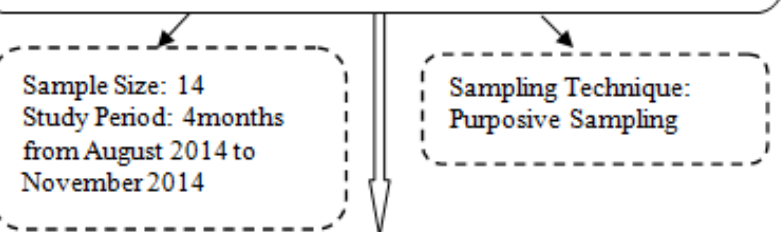

Dietary counselling and educationalmaterial was given to the detected head and neck cancer patients

Anthropometric measurements, clinical history as well as diet recall were taken again during the treatment period.

Follow up period- same set of data were collected on the 7 weeks i.e. at the completion of the treatment and both dietary and medical compliance was checked for all the detected patients.

Analysis of data using SPSS version 16

\section{Table I Cut Off Range Of Compliance}

\begin{tabular}{l|l}
\hline Compliance \% & Class \\
$<40$ & Low Compliance \\
$40-69$ & Moderately Compliance \\
$>70$ & High Compliance \\
\hline
\end{tabular}

\section{RESULTS}

14 patients detected with head and neck cancer were enrolled in this experimental study design. Their ages were classified into 3 categories i.e. <35years as young adults, 3565 years Middle Age and $>65$ years as old age. Among these 14 patients, majority of the patients (6) falls in the Middle age group category. About 13(92.9\%) patients out of 14 were male, and only $1(7.1 \%)$ patient was female affected with head and neck cancer. Socio-economic status of the patients was determined using Kuppuswamy scale 2012. Based on the education and the occupation of the head of the family as well as the income of the whole family, the socioeconomic status of the patients has been determined. Majority of the patients i.e. about $6(42.9 \%)$ patients fall under the category of Lower Middle Class III but only 1 patient falls under the category of Upper Class I. Rest about 2(14.3\%) patients fall under Upper Lower Class IV and about 3 patients fall under the category of Upper Middle Class.

The cancer treatments i.e. Chemotherapy or Radiation therapy or the combination of both are cost effective. So the affordability of the patients for the cancer treatment can be determined by their socioeconomic status.

Medical assessment of the detected patients includes personal medical problem(s), family history and the treatment they are undergoing. Majority of the patients i.e. $7(50 \%)$ out of 14 were detected with Cancer of Mouth, 5(35.7) of them were having Cancer of Throat whereas the rest of the $2(14.3 \%)$ patients were detected with Cancer of Neck.

Anthropometric measurements mainly Weight, Height and MUAC of all the 14 patients were taken first before treatment, during treatment and after treatment. The mean weight of all the detected head and neck cancer patients was found to be $52.51 \mathrm{~kg}$. Majority of the patients i.e. about $10(71.4 \%)$ out of 14patients were having Normal BMI whereas only $3(21.4 \%)$ patients were categorized as Underweight and only $1(7.1 \%)$ patient were categorized as Pre-Obese according to the Asian Classification of BMI. MUAC has been classified into two categories i.e. Malnourished and Normal. The majority of the patients 9 (64.3\%) were normal whereas $5(35.7 \%)$ were categorized as malnourished.

Almost, all the detected head and neck cancer patients exhibit clinical signs and symptoms like headache, dizziness, nausea or vomiting, pain in the mouth, throat, neck, chewing and swallowing problem, loss of appetite etc. These clinical signs and symptoms classified based on the degree of severity i.e. Mild, Moderate, Severe \& Very severe. The Clinical Symptoms score was calculated by assigning the highest score to very severe and lowest score to mild symptoms. The sum total is further classified as $<5$ points to mild, $5-17$ as moderate, $18-27$ as severe and more than 28 points as very severe. Most of the patients i.e. about 8 (57.1\%) were having moderate signs and symptoms, $5(35.7 \%)$ patients were having mild symptoms and only $1(7.1 \%)$ patient had severe clinical symptoms before the initiation of the treatment. The CRT-induced dysphasia, odynophagia, loss of sense of taste, xerostomia, nausea, vomiting and loss of appetite may have a significant negative impact on nutrition and functional ability leading to malnutrition.

The nutritional status of all the detected head and neck cancer patients was determined with the help of a nutritional screening tool i.e. PGSGA (Patient Generated Subjective Global Assessment) tool. The patients were classified under 3 different stages i.e. Stage A - Well nourished, Stage B - 
Moderately malnourished and Stage C - Severely malnourished. They were classified with respect to their health condition and the scores given to them after assessing their health condition. About $3(21.4 \%)$ patients were classified under Stage A. 11(78.6\%) out of 14 head and neck cancer patients were classified under Stage B.

Effect of dietary counseling has been observed based on the following aspects given below:

\section{a. Anthropometry \\ b. Dietary Intake}

Effect Of Diet Counseling On Anthropometric Indices Of The Detected Head And Neck Cancer Patients

Table II. shows the comparison between the pre, during and the post anthropometric measurements of all the patients using the test of Repeated Measures ANOVA.

Table III. shows the pairwise comparison between pre, during and post anthropometric measurements of all the patients using the test of repeated measures.

The tables II \&III depict that when using ANOVA with repeated measures with a Greenhouse - Geisser correction as well as in the pairwise comparison the mean scores of weight were statistically significant $(\mathrm{F}(1.261,16.395)=$ 6.692, $\mathrm{p}=0.015)$ at $5 \%$ level where the reduction is observed in mean weight during the treatment i.e. $50.06 \mathrm{~kg}$ when compared with mean weight $(52.51 \mathrm{kgs})$ before the treatment initiation whereas the mean post weight was slightly increased i.e. $50.53 \mathrm{~kg}$ than the mean weight during the treatment. Similarly, the mean scores of BMI also seemed to be statistically significant ( $F(1.261$, $16.398)=7.142, \mathrm{p}=0.012$ ) at $5 \%$ level with the changes in

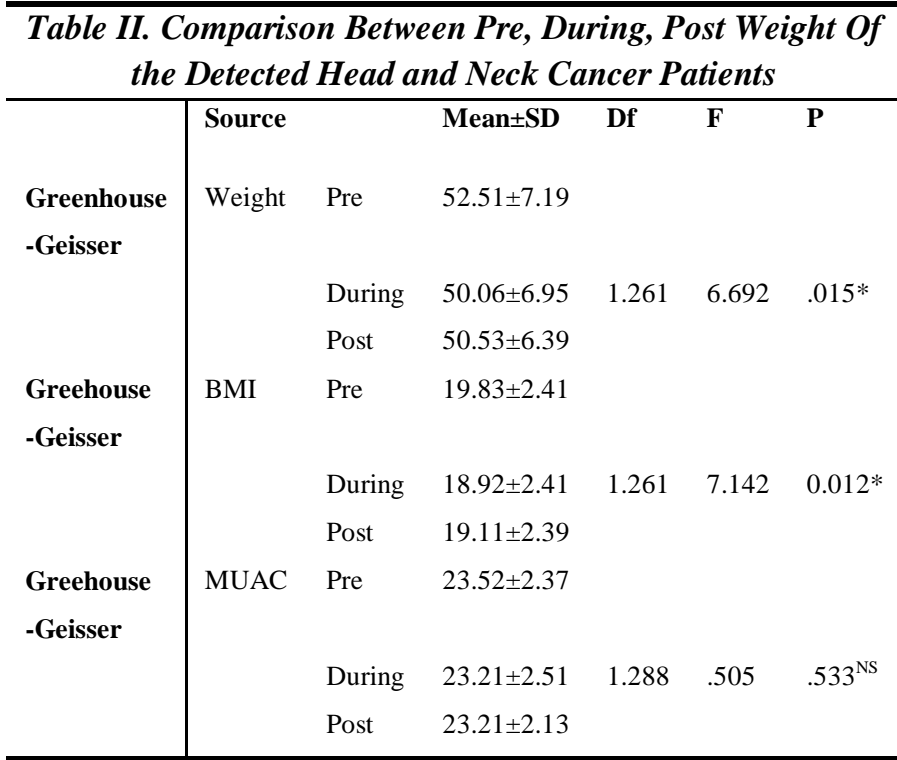

\footnotetext{
weight. However, the mean

**significant at $1 \%$ level, *significant at $5 \%$ level, NS Non significant

score of Mid-upper arm circumference (MUAC) hardly changed when compared between pre, during and post treatment, hence it is non significant.
}

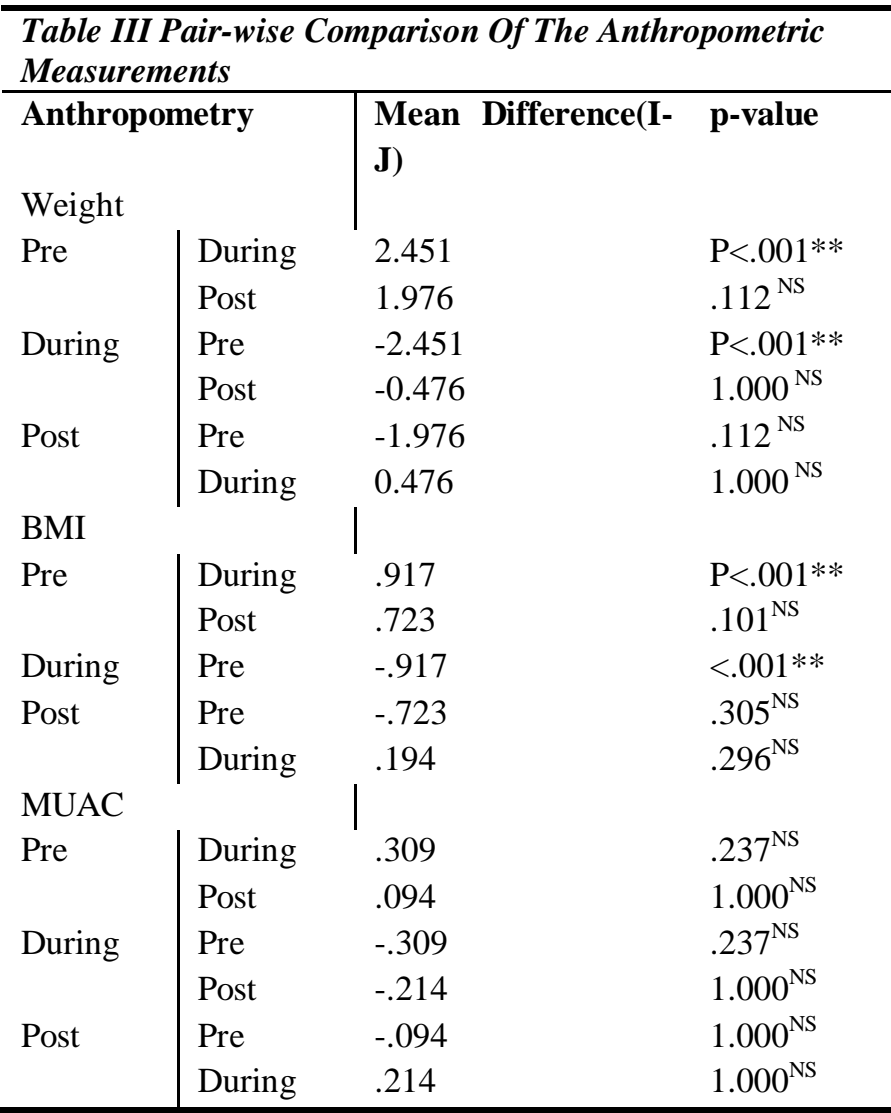

**significant at $1 \%$ level, *significant at $5 \%$ level, NS Non significant

\section{Effect Of Diet Counseling On Dietary Intake Of The} Detected Head And Neck Cancer Patients

Effect of dietary counseling has been observed on the nutrient intake of all the detected head and neck cancer patients.

Both the tables IV and V represent the comparison between the pre, during and the post nutrient intake of all the head and neck cancer patients using the test of Repeated Measures, ANOVA.

The mean scores of energy intake was statistically significant $(\mathrm{F}(1.578,20.518)=4.350, \mathrm{p}=0.034)$ at $5 \%$ level, as the intake had dropped during the treatment but significantly increased as the treatment terminates. The pre mean protein intake was $44.45 \mathrm{gm}$, which had reduced nonsignificantly during the treatment i.e. $43.60 \mathrm{gm}$ but increased significantly post treatment to58.87gm. So the mean scores of protein intake was showing a significant difference $(\mathrm{F}(1.423,18.50)=6.839, \mathrm{p}=0.011)$ at $5 \%$ level. Though the mean intake of carbohydrates seemed to increase slightly among the patients, it is not showing any significant difference. Similarly, fat intake has decreased among the patients post treatment and diet counseling but is not showing any significant difference. Among the micronutrients, the mean score of calcium (F (1.667, $21.674)=18.784, \mathrm{p}<0.001)$ is showing significantly different at $1 \%$ level where the mean post intake has seen to increase drastically. The mean scores of zinc was also showing a significant difference $(\mathrm{F}(1.284,16.694)=4.521, \mathrm{p}=0.041)$ at 5 


\section{Effect of Diet Counseling on Anthropometric Indices and Dietary Intake of the Head and Neck Cancer Patients Undergoing Chemo-Radiotherapy}

$\%$ level as well as the intake of Vitamin $\mathrm{C}$ was also showing a difference $(\mathrm{F}(1.432,18.616)=4.046, \mathrm{p}=0.046)$ at $5 \%$ level which may have increased significantly after counseling. However, the pairwise comparison of these nutrients (Table V) has not shown any significant difference. The mean score of Vitamin B2 $(\mathrm{F}(1.533,19.92)=7.080$, $\mathrm{p}=.008)$ is also significant at $1 \%$ level as well as the

\begin{tabular}{|c|c|c|c|c|c|}
\hline \multicolumn{6}{|c|}{ TableIV Comparison Between Pre, During \& Post Treatment Intake } \\
\hline Source & & Mean \pm SD & Df & $\mathbf{F}$ & $\mathbf{P}$ \\
\hline \multirow[t]{3}{*}{ Energy } & Pre & $1491.61 \pm 306.49$ & 1.578 & 4.350 & $.034 *$ \\
\hline & During & $1397.59 \pm 225.91$ & & & \\
\hline & Post & $1674.07 \pm 327.69$ & & & \\
\hline \multirow[t]{3}{*}{ Protein } & Pre & $44.45 \pm 12.47$ & 1.423 & 6.839 & $.011 *$ \\
\hline & During & $43.60 \pm 14.30$ & & & \\
\hline & Post & $58.87 \pm 19.15$ & & & \\
\hline \multirow[t]{3}{*}{ Fat } & Pre & $46.27 \pm 16.05$ & 1.615 & 2.381 & $.125^{\mathrm{NS}}$ \\
\hline & During & $37.67 \pm 11.52$ & & & \\
\hline & Post & $47.51 \pm 19.69$ & & & \\
\hline \multirow[t]{3}{*}{ Carbohydrate } & Pre & $223.98 \pm 50.67$ & 1.972 & 3.176 & $.059^{\mathrm{NS}}$ \\
\hline & During & $221.01 \pm 40.86$ & & & \\
\hline & Post & $252.86 \pm 44,04$ & & & \\
\hline \multirow[t]{3}{*}{ Calcium } & Pre & $596.89 \pm 221.78$ & & & \\
\hline & During & $664.48 \pm 352.61$ & 1.667 & 18.784 & $\mathrm{P}<.001^{* *}$ \\
\hline & Post & $1151.13 \pm 565.52$ & & & \\
\hline \multirow[t]{3}{*}{ Zinc } & Pre & $5.17 \pm 1.92$ & 1.284 & 4.521 & $.041 *$ \\
\hline & During & $4.84 \pm 2.49$ & & & \\
\hline & Post & $6.89 \pm 3.62$ & & & \\
\hline \multirow[t]{3}{*}{ Iron } & Pre & $9.17 \pm 2.64$ & 1.036 & 2.878 & $.112^{\mathrm{NS}}$ \\
\hline & During & $8.04 \pm 2.56$ & & & \\
\hline & Post & $14.96 \pm 13,97$ & & & \\
\hline \multirow[t]{3}{*}{ Vitamin C } & Pre & $70.04 \pm 46.23$ & 1.432 & 4.046 & $.046^{*}$ \\
\hline & During & $62.76 \pm 43.76$ & & & \\
\hline & Post & $113.21 \pm 77.69$ & & & \\
\hline \multirow[t]{3}{*}{ Vitamin A } & Pre & $376.56 \pm 652.44$ & 1.319 & 5.948 & $.019^{*}$ \\
\hline & During & $679 \pm 1302.92$ & & & \\
\hline & Post & $1482.35 \pm 1835.84$ & & & \\
\hline \multirow[t]{3}{*}{ Vitamin B2 } & Pre & $0.95 \pm 0.44$ & 1.533 & 7.080 & $.008^{* *}$ \\
\hline & During & $1.26 \pm .79$ & & & \\
\hline & Post & $1.74 \pm 1.05$ & & & \\
\hline \multirow[t]{3}{*}{ Folic Acid } & Pre & $148.23 \pm 57.65$ & 1.253 & .963 & $.362^{\mathrm{NS}}$ \\
\hline & During & $140.84 \pm 59.44$ & & & \\
\hline & Post & $176.52 \pm 92.25$ & & & \\
\hline
\end{tabular}

**significant at $1 \%$ level, *significant at $5 \%$ level, NS

Non significant

pairwise comparison is also showing a significant difference at $1 \%$ level when pre intake and post intake was compared.

The intake of Vitamin A has also increased significantly at $5 \%$ level from pre to post treatment which was evident from its mean score $(\mathrm{F}(1.319,17.151)=5.948, \mathrm{p}=.019)$.

Although, the mean scores of iron and folic acid intake is not showing any significance level, their intake has increased non significantly in the post treatment and diet counselling.

The increase in the intake of most of the nutrients were mostly due to the B-Protin nutritional supplement that was prescribed to most of the patients after the treatment has initiated so that they do not experience further loss of their muscle mass.

Table V Pairwise Comparisons of Nutrients Intake Pre, During and Post Treatment

\begin{tabular}{lll}
\hline utrients & Mean & p-value \\
& Difference(I-J) &
\end{tabular}

Energy

Pre During $\quad 94.014 \quad .682^{\text {NS }}$

$\begin{array}{lll}\text { Post } & -182.464 & .421^{\mathrm{NS}}\end{array}$

During Pre $\quad-94.014 \quad .682^{\text {NS }}$

$.028 *$

$421^{\mathrm{NS}}$

$\begin{array}{llll}\text { Post } & \text { Pre } & 182.464 & .421^{\text {NS }} \\ & \text { During } & 276.479 & .028 *\end{array}$

Protein

Pre

During

.851

$1.000^{\mathrm{NS}}$

$.039 *$

During Pre $\quad-.851$

$-.851$

$1.000^{\mathrm{NS}}$

$.051^{\mathrm{NS}}$

Post $\quad$ Pre 14.419

$.039 *$

$.051^{\mathrm{NS}}$

Fat

During

15.270

$.107^{\mathrm{NS}}$

$1.000^{\mathrm{NS}}$

$.107^{\mathrm{NS}}$

$.213^{\mathrm{NS}}$

$1.000^{\mathrm{NS}}$

$.213^{\mathrm{NS}}$

Carbohydrate

Pre During $\quad 2.971$

$1.000^{\mathrm{NS}}$

$.210^{\mathrm{NS}}$

$1.000^{\mathrm{NS}}$

During Pre $\quad-2.971$

$13.204^{\mathrm{NS}}$

$.210^{\mathrm{NS}}$

$.094^{\mathrm{NS}}$

Zinc

Pre During $\quad 330$

$1.000^{\mathrm{NS}}$

$.156^{\mathrm{NS}}$

$1.000^{\mathrm{NS}}$

$.122^{\mathrm{NS}}$

$.156^{\mathrm{NS}}$

$.122^{\mathrm{NS}}$

Calcium

Pre During $\quad-67.587$

$1.000^{\mathrm{NS}}$

$.001 * *$

During Pre $\quad 67.587$

$1.000^{\mathrm{NS}}$

$.002 * *$

Post Pre $\quad 554.237 \quad .001 * *$

During $\quad 486.650 \quad .002 * *$

Iron

Pre

$\begin{array}{ll}\text { During } & 1.130 \\ \text { Post } & -5.786\end{array}$

$.295^{\mathrm{NS}}$ $.406^{\mathrm{NS}}$ 


\begin{tabular}{|c|c|c|c|}
\hline \multirow[t]{2}{*}{ During } & Pre & -1.130 & $.295^{\mathrm{NS}}$ \\
\hline & Post & -6.915 & $.295^{\mathrm{NS}}$ \\
\hline \multirow[t]{2}{*}{ Post } & Pre & 5.786 & $.406^{\mathrm{NS}}$ \\
\hline & During & 6.915 & $.295^{\mathrm{NS}}$ \\
\hline \multicolumn{4}{|c|}{ Vitamin C } \\
\hline \multirow[t]{2}{*}{ Pre } & During & 7.276 & $1.000^{\mathrm{NS}}$ \\
\hline & Post & -43.173 & $.136^{\mathrm{NS}}$ \\
\hline \multirow[t]{2}{*}{ During } & Pre & -7.276 & $1.000^{\mathrm{NS}}$ \\
\hline & Post & -50.449 & $.159^{\mathrm{NS}}$ \\
\hline \multirow[t]{2}{*}{ Post } & Pre & 43.173 & $.136^{\mathrm{NS}}$ \\
\hline & During & 50.449 & $.159^{\mathrm{NS}}$ \\
\hline \multicolumn{4}{|c|}{ Vitamin A } \\
\hline \multirow[t]{2}{*}{ Pre } & During & -302.434 & $.334^{\mathrm{NS}}$ \\
\hline & Post & -1105.791 & $.045^{*}$ \\
\hline \multirow[t]{2}{*}{ During } & Pre & 302.434 & $.334^{\mathrm{NS}}$ \\
\hline & Post & -803.357 & $.158^{\mathrm{NS}}$ \\
\hline \multirow[t]{2}{*}{ Post } & Pre & 1105.791 & $.045^{*}$ \\
\hline & During & 803.357 & $.158^{\mathrm{NS}}$ \\
\hline \multicolumn{4}{|c|}{ Vitamin B2 } \\
\hline \multirow[t]{2}{*}{ Pre } & During & -.302 & $.201^{\mathrm{NS}}$ \\
\hline & Post & -.784 & $.008 * *$ \\
\hline \multirow[t]{2}{*}{ During } & Pre & .302 & $.201^{\mathrm{NS}}$ \\
\hline & Post & -.482 & $.245^{\mathrm{NS}}$ \\
\hline \multirow[t]{2}{*}{ Post } & Pre & .784 & $.008 * *$ \\
\hline & During & .482 & $.245^{\mathrm{NS}}$ \\
\hline \multicolumn{4}{|c|}{ Folic Acid } \\
\hline \multirow[t]{2}{*}{ Pre } & During & 7.395 & $1.000^{\mathrm{NS}}$ \\
\hline & Post & -28.286 & $1.000^{\mathrm{NS}}$ \\
\hline \multirow[t]{2}{*}{ During } & Pre & -7.395 & $1.000^{\mathrm{NS}}$ \\
\hline & Post & -35.681 & $.924^{\mathrm{NS}}$ \\
\hline \multirow[t]{2}{*}{ Post } & Pre & 28.286 & $1.000^{\mathrm{NS}}$ \\
\hline & During & 35.681 & $.924^{\mathrm{NS}}$ \\
\hline
\end{tabular}

**significant at $1 \%$ level, *significant at $5 \%$ level, NS Non significant

Table VI. Evaluation Of The Diet Compliance As Well As Medical Treatment Compliance Of All Detected Head And Neck Cancer Patients

Compliance $\quad$ Frequency $(\%)$

\begin{tabular}{llll}
\hline & Low & Moderate & High \\
Dietary & - & $9(64.3)$ & $5(35.7)$ \\
Compliance & & & \\
\hline
\end{tabular}

\begin{tabular}{|c|c|c|c|}
\hline Medical & $1(7.1)$ & - & 13(92.9) \\
\hline
\end{tabular}

The above table shows that majority of the patients i.e. $9(64.3 \%)$ out of 14 patients detected with head and neck cancer were moderately compliant to the diet therapy and $5(35.7 \%)$ patients were highly compliant to the diet therapy. On the other hand, majority of the patients i.e. 13(92.9\%) were highly compliant and only $1(7.1 \%)$ patient has shown low compliant to medical treatment i.e. chemoradiotherapy.
Table VII. Relationship Between Dietary Compliance (\%) And PGSGA Score

COMPLIANCE (\%)

\begin{tabular}{llll}
\hline & & r-value & p-value \\
Post & PGSGA & -.602 & $.023^{*}$ \\
score & & \\
\hline
\end{tabular}

*significant at $5 \%$ level

The diet compliance $(\%)$ has been correlated with that of post PGSGA score, where the Pearson's correlation (r) value was showing that they are negatively correlated $(r=-.602)$ with each other and showing significantly different $(\mathrm{p}=.023)$ at 5\% level. This means that, if diet compliance is high then the PGSGA score will decrease which is an indication of improved nutritional status of the patients.

\section{DISCUSSION}

The diet counselling has a positive impact on the nutritional status of the patients as they often experience a drop in their nutritional status as a result of cancer canchexia, anti- cancer treatments like chemotherapy or radiotherapy and the symptoms they develop after treatment. This is quite evident from this study result which showed an increase in weight among the patients non- significantly. The MUAC also remain unchanged post treatment among these patients which is a positive sign as they have not experienced further muscle mass loss which is the most important indicator of protein energy malnutrition among these patients. However, a better result could have obtained in the weight and MUAC with the extended study period as the improvement in these indices takes place gradually and slowly with improved nutritional intake. This result is supported by a study which indicates that the patients who were receiving individual dietary counseling had a maximum of $3 \%$ unintended weight loss 2 weeks after the treatment [ ]. However another study indicates that this weight loss cannot be completely prevented by nutritional counseling [ ].

The significant changes have also been noticed in the dietary intake of the patients post dietary counselling. The intake of macro nutrients like energy and protein has significantly increased among these patients post treatment and that reflected on their nutritional status. The result is supported by a research study which proves that there was a significant increase in the caloric and protein intake for the three groups i.e. oral group, naso-enteral tube group \& supplement group irrespective of the type of nutritional intervention[ ]. This result is also supported by a study showing that whether the patients were on exclusive oral diet or enteral feeding there was a significant increase in calorie ingestion through supplemented oral diet.[ ] The intake of micronutrients like calcium, zinc, vitamin $\mathrm{C}$, vitamin A, vitamin B2 has also increased significantly after dietary counseling. In addition, the increased nutritional intake also attributed to a nutritional supplement named BProtin that had been prescribed to most of the patients

depending upon their condition and nutritional 
status. Certain nutrients like iron and folic acid did show any significant difference in those patients as they get easily depleted due to the anti-cancer treatment. [ ].

Although better results could have obtained with extended study period, the nutritional counseling have played a crucial role on the improvement of the nutritional status of the detected head and neck cancer patients which further helped in the betterment of the overall health condition of the patients.

\section{ACKNOWLEDGEMENTS}

I would like to thank my research guide Mrs Pallavi G. Shettigar and co-guide Dr H Y Prahlad for their valuable advice and support at all stages of my research.

\section{REFERENCES}

1. (Cancer Research UK) Cancer Research UK. (n.d.). Retrieved from http://www.cancerresearchuk.org/cancerinfo/cancerstats/types/oral/incidence/uk-oral-cancerincidence-statistics:

http://www.cancerresearchuk.org/cancerinfo/cancerstats/types/oral/incidence/uk-oral-cancerincidence-statistics

2. (National Cancer Institute, 2012) National Cancer Institute. (2012, January 2). Retrieved from http://www.cancer.gov/cancertopics/factsheet/SitesTypes/head-and-neck: http://www.cancer.gov/cancertopics/factsheet/SitesTypes/head-and-neck

3. (Agostino Paccagnella, 2010) Agostino Paccagnella, M. M.-R. (2010). Early intervention improves treatment tolerance and outcomes in head and neck cancer undergoing concurrent chemoradiothera.

4. (Harriët Jager-Wittenaar \& Pieter U. Dijkstra \& Arjan Vissink \& Rob P. van Oort, 2010) Harriët JagerWittenaar \& Pieter U. Dijkstra \& Arjan Vissink \& Rob P. van Oort, B. F. (2010). Malnutrition in patients treated for oral or oropharyngeal cancer-prevalence and relationship with oral symptoms: an explorative study. 1675-1683.

5. (Roodenburg, 2010) Roodenburg, H. J.-W. (2010). Malnutrition in patients treated for oral or oropharyngeal cancer-prevalence and relationship with oral symptoms: an explorative study. 1675-1683.

6. (Ji-Yeon Kim, 2011) Ji-Yeon Kim, G. A.-A.-Y.-M.-H.J.-H. (2011). Development and validation of nutrition screening tool for hospitalized cancer patients. Clinical Nutrition, 724-729.

7. (J.Bauer, 2002) J.Bauer, S. (2002). Use of Scored Patient Subjective Global Assessment(PG-SGA) as a nutrition assessment tool in patients with cancer. European Jaounal of Nutrition .

8. (Manon G. A. van den Berg, Comparison of the effect of individual dietary counselling and of standard nutritional care on weight loss in patients with head and neck cancer undergoing radiotherapy, 2010). Manon G. A. van den Berg, E. L.-C.-L. (2010). Comparison of the effect of individual dietary counselling and of standard nutritional care on weight loss in patients with head and neck cancer undergoing radiotherapy. British Journal of Nutrition , 872-877.

9. (Manon G. A. van den Berg, Comparison of the effect of individual dietary counselling and of standard nutritional care on weight loss in patients with head and neck cancer undergoing radiotherapy, 2010) Manon G. A. van den Berg, E. L.-C.-L. (2010). Comparison of the effect of individual dietary counselling and of standard nutritional care on weight loss in patients with head and neck cancer undergoing radiotherapy. British Journal of Nutrition 872-877.

10. (Michele, 2009) Michele, A. P.-R. (2009). Early nutritional intervention improves treatment tolerance and outcomes in head and neck cancer patients undergoing concurrent chemoradiotherapy. Support Care Cancer , 837-845.

11. (M. C. Gonçalves Dias, 2005) M. C. Gonçalves Dias, M. d. (2005). Nutritional intervention improves the caloric and proteic ingestion of head and neck cancer patients under radiotherapy. Nutricion Hospitalaria , 320-325.

12. (McCarthy D, 1999) McCarthy D, W. D. (1999). The effect of supplementation on food intake in patients undergoing radiotherapy. Oncol Nurs Forum , 897-900.

13. (M.Dicato, 2010) M.Dicato, L. M. (2010). Anemia in Cancer. Annals of Oncology, 68. 